\title{
Buy The Rumor, Sell The News! What About Takeover Rumors?
}

\author{
Mhammed Laouiti, Faculty of Economics and Management of Sfax, Tunisia \\ Badreddine Msolli, ESSCA School of Management, Lunam University, France \\ Aymen Ajina, Arab East Colleges-Riyad, Saudi Arabia
}

\begin{abstract}
This paper attempts to quantify the short-term impact of takeover rumors on target stock prices. The study was conducted on the French stock market between 1997 and 2011 and concerns 200 rumors that appeared in the media (news agencies, newspapers, and Web sites). Our results show that this particular kind of information has a significant impact on the prices of target companies around and after the date of rumor appearance. The best performance of target shares is observed 50 days after the dissemination of the rumors in the media, with an average return of 4\%. This performance is mainly explained by three components: credibility, rumor characteristics, and the anticipated effects of the takeover bid.
\end{abstract}

Keywords: Takeover Rumors; Event Study; Buy-And-Hold

\section{INTRODUCTION}

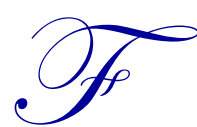

inancial rumors are seen as the natural consequences of any financial market (Kapferer, 1990). They emerge as important and uncertain information, in clear opposition to the notion of perfect information promoted by the stock exchange regulatory authorities. The last few years have seen on the French stock market the emergence of a particular kind of financial rumors, namely those linked to takeover bids, which have received particular attention from diverse quarters, and especially from the French financial markets authority (Autorité des marchés financiers - AMF). For instance, the Danone Group was rumored to be the target of a takeover by the American group, PepsiCo, in July 2005. Two months after their first appearance, the rumors brought a considerable $30 \%$ impact on the target share prices. In the end, no offer was submitted, but the rumor led to the intervention of the Prime Minister who raised the issue of "the risks of French companies being controlled by foreign capital." Similarly, in February 2006, there were rumors that the Suez Company was targeted by the Italian company ENEL. This rumor also led to an intervention from the then Prime Minister who asserted that this type of bid is seen as an attack against France. ${ }^{1}$

In October 2006, responding to these two events, the AMF developed a procedure for dealing with market rumors; this procedure became law ${ }^{2}$. This law requires all companies that are subject to significant and unusual price and/or volume variations to report their intentions and, where appropriate, file a public exchange offer.

Recently, at the end of 2010, this law forced the LVMH Group to declare its intentions regarding the Hermès Group when LVMH was found controlling $17 \%$ of its voting rights after a covert stake increase. Questioned by the AMF, the LVMH Group denied wishing to launch a takeover bid on Hermès whose family members had started preparing a counter-offer to save the Group. During the week of December $3^{\text {rd }}, 2010$, the Hermès share price went up about $12 \%{ }^{3}$

${ }^{1}$ French press office (AFP), February 23rd, 2006.

${ }^{2}$ Section 7, article 223-32 of the General Regulation of the AMF.

${ }^{3}$ The first declaration of threshold crossing occurred on October 27th, 2010, at the 14.22\% level. On December 21st, 2010, LVHM owned 20.21\% of the capital and $12.73 \%$ of voting rights. See http://www.amf-france.org (threshold crossing). 
Despite the ubiquitous and substantial reality of takeover bid rumors on the French stock market, no study has focused on the impact and consequences of this phenomenon. Most studies have focused on the U.S. market (Pound and Zeckhauser, 1990; Zivney et al., 1996; Gao and Older, 2008) or the Australian market (Clarkson et al., 2006). Those studies have shown that takeover bid rumors published only in the Wall Street Journal (U.S. studies) and the discussion site Hotcopper.com (Australian market) cause a positive reaction of the target share prices mainly before and on the day of their publication. However, findings related to the short-term performance of those shares after the spread of rumors are contradictory. Pound and Zeckhauser (1990) conclude that the market reacts efficiently to the journal announcement, and a buy-and-hold strategy does not benefit the holders of the target shares. This study is criticized by Zivney et al. (1996) who assert that the rumors collected by Pound and Zeckhauser (1990) had already been published in the "Abreast of the Market" (AOTM) column of the journal. The findings of Zivney et al. (1996) show a positive performance over the 100 days following the date of the first publication. Along the same lines, and focusing again on the U.S. market, Gao and Older (2008) find positive abnormal returns over the 70 days following the publication of the rumors. These three studies focus solely on the rumors that appeared in the Wall Street Journal columns, which increases the risk of error regarding the first dates of publication of the rumors since rumors may appear in other sources before the journal picks them up.

Against this background, this paper focuses on the study of the impact of takeover bid rumors on share prices and of the short-term performance of the share prices of target companies listed on the French Stock Exchange. This will result in a first evaluation of the consequences of this phenomenon on the target shares and a proposal for an appropriate investment strategy based on their short-term performance. Furthermore, we propose to show the potential profit for the shareholders in terms of not only the characteristics of rumors but also certain indicators of the target companies. Indicators are used in the studies on the identification of the determining factors for the premium offered to the shareholders of target takeover companies.

This study is intended mainly for portfolio managers and particularly the shareholders of target companies who are seeking a potential capital gain. Greater understanding of the behavior of target prices will also provide answers to the excessive volatility observed when this type of rumors occurs, which should be of interest to regulatory and Stock Exchange agencies.

Our paper is divided into four parts. First, we present the review of the literature devoted to measuring the impact of takeover rumors and determining the performance of the target companies. We then outline the strategy for rumor collection and our methodological approach, and lastly we present and interpret our findings.

\section{The Determining Factors of the Behavior of the Share Prices of Companies Subject to Takeover Rumors}

\section{The Potential Gain for The Shareholders of Companies Subject to Takeover Rumors}

From a financial perspective, the study of mergers and acquisitions has shown inequitable profit sharing, ranging from $20 \%$ to $40 \%$, that benefits the shareholders of the target companies (Goergen and Renneboog, 2004). Various studies also mention an abnormal positive reaction of the target share prices mainly preceding the official announcements of the takeover bids. The abnormal share behavior is mainly due to the possible rumors circulating in the media that precede the formal announcement of the takeover (Keown and Pinkerton, 1981; Jarrell and Poulsen, 1989; Gao and Older, 2008). A number of studies have since focused on the impact of the takeover rumors on the share prices of target companies and on the expectation of potential gains through speculation solely based on this type of information.

Most of the studies devoted to this issue are U.S.-based and focus essentially on takeover rumors published in the Wall Street Journal. The methodology of event study is used to measure the reaction of the share prices around the dates of the emergence of rumors in the media. Pound and Zeckhauser (1990) investigate the behavior of the share prices of 42 companies that were the subject of takeover rumors published in the "Heard on the Street" column. The authors noted a total of abnormal returns of $7.5 \% 20$ days before the publication of rumors in the journal. Similarly, Zivney et al. (1996) indicate that certain rumors that were published in "Heard on the Street" had appeared on average 10 days earlier in the AOTM column in the same journal. These findings clearly show a significant reaction of share prices with average abnormal returns of $7.78 \%$ over the 20 days preceding the publication of the rumors. 
Conversely, and contrary to the findings of Pound and Zeckhauser (1990), the authors identify an investment strategy involving buying shares the day the rumors appear in AOTM and selling them 80 days later. The target share performance on that retention period is $6.35 \%$ on average. Still focusing on the U.S. market, Gao and Older (2008) analyze the behavior of shares that were the target of 159 takeover rumors published in the Wall Street Journal between 1991 and 2001. Gao and Older show that the strategy consisting in buying shares targeted by takeover rumors and keeping them for 70 days provided average abnormal returns of $4.5 \%$ for the total sample. As far as the Australian market is concerned, Clarkson, Joyce and Tutticci (2006) analyze the impact of the takeover rumors posted on the Hotcopper Internet discussion site (www.hotcopper.com) between May 1st, 1999, and March 31 st, 2000. Clarkson et al. found significant abnormal returns of $1.09 \%, 2.95 \%$, and $2.37 \%$ respectively, two days before and on the same day the rumors appeared. The intraday analysis also showed abnormal returns 60 minutes before the rumors appeared and 10 minutes afterwards.

Based on these findings, we also hypothesize that takeover rumors will result in a positive reaction of the shares prices of the companies listed on the French Stock Exchange.

\section{Determinants of The Premium Offered to The Shareholders of the Companies Subject to Takeover Rumors}

Very few studies have sought to explain the short-term performance of stock prices subject to takeover rumors. A spate of studies has instead focused on the identification of the determinants of the premium offered to the shareholders of the target companies. These investigations obviously take into account those characteristics of the target companies that make them possible takeover targets. Based on these findings, we hypothesize that the possible reaction of the shares of companies subject to takeover rumors can depend on three categories of variables: credibility, rumor characteristics, and the takeover expected effects.

\section{Rumor Credibility}

This category incorporates variables that give greater plausibility to the imminence of the takeover bid. Laouiti (2014) shows that rumoured target's firms have approximately the same characteristics of the ones identified as potentially takeover by the acquisition prediction models. Credibility is thus embodied in those company characteristics that, to some degree, appear to facilitate the execution of the takeover, hence increasing the investors' belief. This could, in the end, impact on the short-term performance of the target share prices. The company characteristics are the following:

\section{a. Size}

Takeover bids usually target small companies. Palepu (1986) asserts that as the costs of the buy-out increase with the size of the target company, the larger the company, the less chance of success of the bid. Size is expressed in terms of the logarithm of the market capitalization or that of the total assets. Similarly, Clarkson et al. (2006) find that the abnormal returns are negatively related to the size of companies subject to takeover rumors on the Australian market. Martynova and Renneboog (2011) measure the effect of size by the ratio of target size to acquiring size and find no significant relation with the bids-connected abnormal returns. Hence, we hypothesize that there is a negative relationship between the size of companies subject to takeover rumors and the abnormal returns generated by the appearance of takeover rumors.

\section{b. Sector Affiliation}

Cudd and Duggal (2000) measure sector affiliation through a binary variable and show that, apart from their small size, the acquired companies did belong to sectors that were marked by a takeover bid during the year preceding the official announcement of the operation. In terms of the relationship with abnormal returns, Clarkson et al. (2006) test the effects of the affiliation of the targets to those sectors most targeted by takeover rumors on the Australian market, but no significant relationship with the abnormal returns found was established. In the same context, Goergen and Renneboog (2004) find that there was no significant explanation of the abnormal behavior of share prices that could be linked to the target and the bidding companies belonging to the same industry sector. We thus 
hypothesize that there is a positive relationship between the abnormal returns generated by the rumors and the sector affiliation variable.

\section{c. The free float percentage}

By definition, the free float of a company corresponds to the part of capital that is dispersed among private investors and not held by stable shareholders. A large proportion of free float indicates that the company's capital is not sufficiently protected against possible takeover operations; hence, the larger the free float, the greater likelihood of the company being the target of a takeover bid. When comparing the impact of takeover bids in Europe, Goergen and Renneboog (2004) find that target UK companies had the highest abnormal returns. The authors explain that these companies are characterized by a higher proportion of free float than that of companies listed in Continental Europe. We thus hypothesize that the size of the free float explains the potential gains realized by the shareholders of companies subject to takeover rumors.

\section{d. Undervaluation}

Hasbrouck (1985) suggests that acquiring an underevaluated company is a worthwhile financial opportunity for buyers. If the bid is successful, the target company should regain at least its basic value, and the buyer will benefit from the premium. Hence, Rau and Vermaelen (1998) have shown that acquiring underevaluated companies (low market-to-book ratio or high book-to-market ratio) generates considerable abnormal returns. We hypothesize that there exists a positive relationship between the abnormal returns of companies subject to takeover rumors and the market-to-book ratio.

\section{Rumor Characteristics}

This model dimension brings together the variables related to the messages of takeover rumors that may increase their credibility without confirming or denying them.

\section{a. Intensity of Publication}

The more widespread rumors are, the more attention they attract, and so the greater likelihood that they are believed (Kapferer, 1987). Thus, we hypothesize that those rumors most widely reported in the media are those that will have a greater impact on the share prices of takeover target companies.

\section{b. Evidence-Based Arguments}

Rumors may appear on their own or bolstered by evidence that justifies their emergence and increases credibility. Rumor justifications concern mainly information related to the prospect of takeover regarding the target companies (agency issues, low performance, capital movements). We hypothesize that evidence-based or closely argued rumors will attract investors' attention and have a greater impact on the share prices of takeover target companies.

\section{c. Time of Appearance}

According to Kimmel (2004), rumors usually emerge in times of growth and lack of communication. In our study, we measure the volume of information related to takeover bids to identify the time of appearance of rumors in terms of the communication type and possibly the number of rumors. Apart from the communication type and depending on the French Stock Exchange regulations, two distinct periods of rumor appearance have emerged. Since October 2006 and to deal with the excessive volatility of the share prices of takeover target companies, the AMF has adopted a law forcing the parties involved in this type of rumors to declare their intentions and possibly file a public tender offer. Hence, we hypothesize that this type of regulations will mitigate the impact of the takeover rumors. 


\section{Motivations and Expected Effects of the Takeover}

Apart from credibility and rumor characteristics, a third variable category can help account for the short-term performance of the target share prices. The likelihood of the launch of the public bid depends partly on the buyer's motivation to control a specific target company (synergies, efficiency of the target's management team, agency issues). Hence, the more the target of the takeover rumors displays the kind of target characteristics that are in line with those advocated in the theory, the more investors will believe that the bid is imminent, and the more significant the stock price reaction will be.

\section{a. Financial Synergies}

The acquisition is justified by a degree of financial resources complementarity between the target and its buyer. In this respect, Palepu (1986) and Barnes (1999) conclude that an appropriate balance is struck by the effects of synergies between heavily-indebted companies and those with little debt. A low debt ratio involves the target's unused capacity to incur debt, whereas a heavy debt will inhibit acquisition. Jensen (1988) asserts that the size of the premium offered to the target shareholders will be larger when the acquired companies have a substantial debt capacity, namely a low debt ratio (long-term debt/ equity capital).

\section{b. Efficiency of the management team}

Corporate mismanagement will affect performance and make companies potential takeover targets. Hence, replacing an ineffective management team may be argued to justify a takeover. Improving the target performance after the bid launch is thus subject to the new leadership being more effective than their predecessors. Manne (1965) and Palepu (1986) note that there is a negative relationship between the likelihood of acquisition and the performance of target companies before the bid announcement. Furthermore, Servaes (1991), discussing the premium offered to the target shareholders, notes that there is a negative correlation between the performance of acquired companies (as measured by Tobin's $\mathrm{Q}$ ratio) and the observed abnormal returns. Hence, we expect to find a negative relationship between Tobin's $Q$ ratio and the potential gain of shareholders of companies subject to takeover rumors.

\section{c. Agency Issues}

The free cash flow theory (Jensen, 1988) stipulates that the buildup of cash flow could cause conflicts between the shareholders and the leadership because the latter could use the financial surplus to build their managerial empires, in particular by carrying out unprofitable acquisitions to the detriment of the shareholders, who are mainly interested in high dividends. The theory postulates that accumulating free cash flow could make some companies potential targets of takeover bids (Powell, 1997). In these cases, the main motivation for the acquisition is the free cash flow that the acquiring companies see as a financial resource. Furthermore, Lehn and Poulsen (1989) establish a positive relationship between the abnormal returns linked to takeovers and the volume of free cash flow available in the target companies.

\section{DATA, SAMPLE, AND METHOD}

\section{Rumor Collection}

The takeover rumors were collected from the Factiva ${ }^{4}$ database, between 1997 and 2011 on the French Stock Exchange. All information relating to the characteristics of the target companies were collected from the Thomson One Banker and Datastream databases.

The keywords used to collect rumors were the following: acquisition rumors, buy-out rumors, takeover rumors, takeover bids, and tender offers. This phase was followed by a review of the relevant literature. We ruled out all articles dealing with (1) announcements of takeover bids or other types of acquisition or buy-out particularly linked

${ }^{4}$ The database used gives access to over 10,000 sources of information, including 2,000 national and regional daily newspapers; see http://scd.ubordeaux4.fr/Bibli/RE/Guides/Factiva/Memento\%20Factiva.pdf 
to the activity of companies, (2) companies that were not listed on the French Stock Exchange, and (3) repeated rumors: when several articles dealt successively with the same rumor, only the first publication date was included ${ }^{5}$.

We thus kept 200 rumors that had appeared on Euronext Paris between 1997 and 2011.

The keyword-based search led to a number of articles published mainly in French daily newspapers (Le Monde, Le Figaro, Les Échos, La Vie Financière). To make sure we identified the first date of rumors, we carried out a second search on google.fr, which helped identify three categories of rumors according to the source of dissemination: first, the print media (50 rumors); second, Internet sites such as boursorama.com, boursier.com, capital.fr, investir.com (66 rumors); finally, combined sources ${ }^{6}$ including rumors that had appeared in several sources such as press agencies (Reuters and the French press office Agence Française de Presse - AFP) and others (Internet sites and/or newspapers); this last category comprised 84 rumors.

Out of the 200 rumors we retained, $12.5 \%$ are confirmed ${ }^{7}$. This percentage is higher than the one found by Clarkson et al. (2006) regarding the rumors circulating on the forum Hotcopper.com concerning the Australian stock market (11.8\%), but it is lower than the percentage found by Pound and Zeckhauser (1990) (42.26\%) or by Zivney et al. (1996) (29.14\%) regarding the rumors that appeared in the Wall Street Journal concerning the U.S. market. Those rumors that were left out were neither confirmed nor disproved; they represented over half of the entire set of collected rumors. This type of rumors is in keeping with the communication policy carried out by some companies that will not comment on speculations and rumors regarding their share prices unless they are forced to do so, in particular by the AMF.

The analysis of the rumors collected according to the time of appearance revealed an important flow of information related to takeovers over the first five months of the year. ${ }^{8}$ There were also a considerable number of rumors in the months of January and April. ${ }^{9}$

\section{Target Characteristics}

To identify the characteristics of companies subject to takeover rumors, we classified our rumor sample according to the three compartments of listings on the French Stock Exchange and the business sectors. Table 1 shows the analysis according to the size of the companies: there are 132 companies in Compartment A, 38 companies in Compartment B, and only 30 companies in Compartment C. It thus appears that takeover bid rumors target companies with large market capitalization. In this particular case, the importance of the rumor shows the importance of the target, particularly in terms of market capitalization.

The sample analysis according to company size also shows that market capitalization varies between a minimum of 1 million Euros and a maximum of 101,407 million Euros (see Table 1).

Table 1. Sample distribution by listing market

\begin{tabular}{l|cccc}
\hline & \multicolumn{4}{c}{ CAP in Million Euros } \\
\hline \multicolumn{1}{c|}{ Compartments } & Rumor targets & MIN & Average & MAX \\
\hline Compartment A & 132 & 1006 & 16638 & 101407 \\
Compartment B & 38 & 162 & 544 & 994 \\
Compartment C & 30 & 1 & 50 & 130 \\
Whole sample & 200 & 1 & 5744 & 101407 \\
\hline
\end{tabular}

\footnotetext{
${ }^{5}$ The intensity of the spread of rumors is examined through the definition of a binary variable.

${ }^{6}$ Very few rumors appeared in press agencies only. Rumors in this category first appeared in press agencies, and then were taken up by Internet sites, newspapers, or both, on the same day.

${ }^{7}$ Confirmed rumors targeted companies that were the subject of a takeover plan with the AMF during the year rumors appeared.

${ }^{8}$ A word-based search was carried out on the Factiva database to obtain an approximate measure of the level of information regarding takeovers.

We noted a particularly high communication level in the first five months of the year.

${ }^{9}$ Out of the 200 rumors collected, 115 appeared in the first five months of the year; 30 appeared in January and 28 in April.
} 
Compartment A: large capitalizations over 1 billion Euros. Compartment B: medium capitalizations between 1 billion Euros and 150 million Euros. Compartment C: small capitalizations below 150 million Euros.

In terms of the Industry Classification Benchmark (ICB) classification, the sample companies are distributed into 9 sectors including mainly consumer services (5000), industry, financial institutions (8000), technology (9000).

Table 2. Sample distribution by business sector

\begin{tabular}{rlcclc}
\hline $\mathbf{N}^{\circ}$ & \multicolumn{1}{c}{ Business sectors } & Rumor targets & $\mathbf{N}^{\circ}$ & \multicolumn{1}{c}{ Business sectors } & Rumor targets \\
\hline 0001 & Oil and Gas & 3 & 5000 & Consumer services & 39 \\
1000 & Basic materials & 10 & 6000 & Telecommunication & 11 \\
2000 & Industries & 34 & 7000 & Utilities & 4 \\
3000 & Consumer goods & 25 & 8000 & Financial companies & 36 \\
4000 & Health & 5 & 9000 & Technology & 33 \\
\hline
\end{tabular}

Notes: The sectors are classified according to the Industry Classification Benchmark. The numbers represent the industry codes. The source of the data is the Datastream database.

On the Australian market, Clarkson et al. (2006) show that the companies most targeted by takeover bid rumors are found in the sectors of basic materials, media, telecommunications, and various industries.

\section{Measurement of The Variables and Presentation of the Model}

Measure of Rumor Impact

Event study methodology ${ }^{10}$ was used to examine the reaction of the target companies share prices at the time of the appearance of the rumors (Fama et al., 1969).

In this approach, the market reaction to new information can be measured by the difference between the returns actually observed on the market and a theoretical norm that corresponds to the estimated returns in the absence of the event. Event study is applied to prices, volume of transactions, and price range.

The event study approach is the same for all types of events. It is usually implemented in four stages:

Stage 1: Determining the study parameters

The study parameters relate mainly to the event date, the time frame, and the study window.

\section{Event and Event Date}

The date of the main event of our study corresponds to the date of the first appearance of the rumors in the media. Collecting rumors from the Factiva database provided access to several sources, namely Internet sites, newspapers, or press agencies. This source diversity brought increased precision regarding the date of the first appearance of the rumors, which reduced the risk of errors, in contrast to that revealed in the previous studies that focused on rumors collected from one source only.

The time frame or sample period: Armitage (1995) shows that the length of sample periods is usually comprised between 100 and 300 days. Estimation of the standard is thus placed on the interval [-260, -21] before the date of appearance of rumors.

The study window: it corresponds to the observation period of the stock price reaction around the event date t0. The period varies from 10, 20, to 40 days around the announcement date (Armitage, 1995). Following Pound and Zeckhauser (1990) and Zivney et al. (1996), our study window is spread over the 40 days around the date of appearance of the rumors in the media, namely 20 days before and 20 days after the event date $t 0$.

\footnotetext{
${ }^{10}$ Event study methodology was first applied to measure the impact of capital increases on the trading price of U.S. securities. Since then, the method has been used in several studies, whether in the domain of finance or that of other disciplines.
} 
Stage 2: Estimating the standard

Over the time frame, the expected profitability in the absence of event is determined through different methods. The market model approach is the most commonly used. The market model developed by Fama et al. (1969) provides an estimate of the expected profitability of the shares in terms of the risk incurred and the marked return. Within this framework, Brown and Warner (1985) carry out simulations and obtain the best results with the market model best adapted to this type of approach.

Stage 3: Calculating abnormal returns

Applying the market model to determine the expected returns on the event window first involves estimating the market model coefficients in terms of the securities returns and the market index in the time frame.

An ordinary least squares regression method is applied:

$$
R_{i t}=\alpha_{i}+\beta_{i} R_{m t}+\varepsilon_{i t}
$$

where: $\mathrm{t} \in[-260,-21]$

Rit: returns of share $\mathrm{i}$ at date $\mathrm{t}$;

$\mathrm{R}_{\mathrm{mt}}$ : returns of market index at date $\mathrm{t}$. In our study, we use the SBF 120 index. Index selection was governed by the size of our sample, but also by the company characteristics, particularly that of size. Most of our sample companies were in compartment A that includes the largest capitalizations quoted on the French Stock Exchange.

$\varepsilon_{i t}:$ model error

$\alpha_{i}$ et $\beta_{i}$ : coefficients to be estimated through the ordinary least squares method.

The estimation results show the following expected returns for each company in the study window, in terms of the estimated coefficients in the time frame:

$$
E\left(R_{i \tau}\right)=\hat{\alpha}_{i}+\hat{\beta}_{i} R_{m \tau}
$$

where: $t \in[-20,+20]$

$E($ Rit) : expected returns in the absence of event of share $i$ at date $t$;

$R_{m t}$ : returns of SBF 120 index at date $t$,

$\hat{\alpha}$ et $\hat{\beta}$ : are the coefficients estimated through the ordinary least squares method.

If the takeover bid rumors include relevant information for investors, they should be accompanied by a price reaction showing abnormal returns in the study period.

This reaction is measured through the difference between the observed returns and the theoretical returns as calculated in the study window.

$$
\begin{aligned}
& R A_{i t}=R_{i t}-E\left(R_{i t}\right) \\
& R A_{i t}=R_{i t}-\left(\hat{\alpha}_{i}+\hat{\beta}_{i} R_{m t}\right)
\end{aligned}
$$


where:

Rit: returns of share $i$ in the estimation period

Rmt: returns of the index, the index used was SBF 120

$\hat{\alpha}_{i}$ et $\hat{\beta}_{i}$ : coefficients estimated through the ordinary least squares method in the time frame.

Once the abnormal returns have been calculated for each company, an average is calculated for the whole sample for each of the 41 days of the study window.

$$
R A M_{t}=\frac{1}{200} \sum_{i=1}^{200} R A_{i t}
$$

where: $\mathrm{t} \in[-20,+20]$

The short-term performance of the target stock prices subject to takeover rumors is also measured in terms of the returns generated by applying a buy-and-hold strategy. Barber and Lyon (1997) explain that this strategy provides a measure of the investors' experience over the period under study. The authors recommend using this estimator to calculate short-term performance.

The returns generated by the buy-and-hold strategy (BAHAR) are estimated for each company in our sample and measured according to the following formula:

$$
\operatorname{BAHAR}_{i t}=\prod_{t=0}^{T}\left(1+r_{i t}\right)-\prod_{t=0}^{T}\left(1+E\left(r_{i t}\right)\right)
$$

where: rit : observed returns of share $i$ at date $t$

$\mathrm{E}(\mathrm{rit})$ : expected returns of share $\mathrm{i}$ at date $\mathrm{t}$ estimated through the market model.

The average returns are then calculated over various hold periods ${ }^{11}$ according to the following formula:

$$
\overline{B A H A B}_{t}=\frac{1}{200} \sum_{i=0}^{t} B A H A R_{i t}
$$

The tests are applied on the averages of the abnormal values observed for the whole sample according to the hypothesis $\mathrm{H}_{0}$ that the $\mathrm{RAM}_{\mathrm{t}}$ and the BAHRt are equal to zero. The significance tests of Sign, the Wilcoxon signedrank test, and the cross-sectional Student test are used for results validation.

The Sign test involves estimating the statistics $Z_{1}$ according to the formula below. Under hypothesis $H_{0}, Z_{1}$ follows a standard normal distribution.

$$
Z_{l}=\frac{N_{+}-\frac{\left(N_{+}+N_{-}\right)}{2}}{\sqrt{\frac{\left(N_{+}+N_{-}\right)}{4}}} \cong N(0,1)
$$

\footnotetext{
${ }^{11}$ The periods change in 10-day intervals from the date 0 of the appearance of rumors. The periods vary from 10 to 150 days after the announcement. Gao and Older (2008) used two methods to calculate the abnormal returns in the study windows. 70 days after the rumors had appeared in the Wall Street Journal, the authors found a difference between the two measures (cumulative abnormal returns of $4.29 \%$ and abnormal returns generated by the buy-and-hold of $4.5 \%$. Both values are positive at the $10 \%$ level.)
} 
$N_{+}$and $N_{-}$are respectively the number of abnormal values (returns, volumes, and price ranges) strictly positive and negative at a given date.

The Z2 statistics also follows a standard normal distribution and is estimated through the Wilcoxon rank test on a self-matched sample that can take into account both the sign of abnormal performance and the amplitude.

$$
Z_{2}=\frac{W_{n}^{+}-\frac{n(n+1)}{4}}{\frac{1}{24} n(n+1)(2 n+1)} \cong N(0,1)
$$

The test is calculated as follows: In a sample n (200), the abnormal returns in absolute value are first sorted in ascending order. To each abnormal value $i$ is attributed a rank Kit in terms of its position. Each rank is then multiplied by the indicator variable $l_{R^{+}}$that is equal to 1 if the observed abnormal value is positive; 0 if not, the sum of the multiplications is equal to the coefficient $W_{n}^{+}=\sum_{t=1}^{200} K_{i t} I_{R^{+}}$

The cross-sectional Student test is calculated as follows:

$$
\theta=\frac{R A M_{t}}{\hat{\sigma}\left(R A M_{t}\right)} \cong T(199)
$$

where

$$
\hat{\sigma}\left(R A M_{t}\right)=\frac{1}{\sqrt{200}} \hat{\sigma}\left(R A_{t}\right)
$$

and

$$
\hat{\sigma}\left(R A M_{t}\right)=\frac{1}{\sqrt{200}} \hat{\sigma}\left(R A_{t}\right)
$$

Measuring the Determining Factors

As previously suggested, the potential gain for the shareholders of the target companies is explained in terms of three categories of variables whose associated measures are presented below. A linear regression calculated by the ordinary least squares method is then applied to the investors' maximum gain as measured through the abnormal returns of the buy-and-hold BAHARi.

$$
\begin{aligned}
& B A H A R i=\beta_{0}+\beta_{1} T A I L L E i+\beta_{2} S E C T i+\beta_{3} F L O T T i+\beta_{4} S E V i+\beta_{5} S C i+\beta_{6} A R G_{i}+\beta_{7} P E R I O \\
& +\beta_{8} R E G+\beta_{9} E N D E T T+\beta_{10} E E D+\beta_{11} F C F+\varepsilon_{i}
\end{aligned}
$$

\section{Rumor Credibility}

The size, sector affiliation, free float percentage, and undervaluation of the target are variables that give sense to the takeover rumor, hence increasing its credibility for investors.

The SIZE variable shows the size of the target company and is measured in terms of the total assets logarithm. SECT is a binary variable equal to 1 if the target belongs to a sector targeted by a takeover bid during the year preceding the appearance of rumors and to 0 if not. Flott determines the percentage of the target capital released to the public 
and not held by the main shareholders, expressed as square root. $S E V$ is a variable that measures the undervaluation of the target; it is expressed in terms of the market-to-book ratio.

\section{$\underline{\text { Rumor Characteristics }}$}

Rumor characteristics are mainly expressed through three variables: $S C$ is a binary variable that shows the dissemination intensity; it is equal to 1 if the rumor has appeared in several sources and to 0 if not. $A R G$ is a binary variable equal to 1 if the rumor is accompanied by details concerning the motivation behind the bid and to 0 if not. PERIO is a binary variable equal to 1 if the rumor appeared during the first five months of the year and to 0 if not. $R E G$ is a binary variable equal to 1 if the rumor appeared after October 2006 and to 0 if not.

Motivations and Expected Effects of the Takeover

This category brings together variables linked to the characteristics of the target companies that make them potential takeover targets. ENDETT shows the debt capacity of the target companies; it is measured by the long-term debt/ equity capital ratio. EED shows the efficiency of the management team expressed through Tobin's Q ratio. FCF shows a possible agency issue of the target companies, particularly in the case of accumulation

\section{FINDINGS}

\section{Rumor Impact and Short-Term Performance}

The findings of the event study show that there are significant positive abnormal returns the day before and on the day rumors appear, respectively of $0.58 \%$ and $2.66 \%$ (see Table 3 ). These findings are aligned with those of Clarkson et al. (2006) or those of Zivney et al. (1996) that indicate an abnormal reaction of the target companies' shares before the date but mainly on the day of the appearance of the appearance of the rumors. The cumulative abnormal returns calculated in the windows $[-20,-1]$ and $[-10,-1]$ are $1.3 \%$ and $0.78 \%$. Although these values are positive, they are inferior to those found by Pound and Zeckhauser (1990) on the U.S. Stock Exchange. Pound and Zeckhauser found that over the 20 days preceding the appearance of rumors, the cumulative abnormal return was $7.5 \%$ and significantly positive. Zivney et al. (1996), however, pointed out that the rumors had appeared 10 days before in another column of the newspaper.

In our study, determining the date of the first appearance of rumors led us to diversify the data collection sources, thus reducing the risk of error in publication dates. This could possibly explain why there are low cumulative abnormal returns before the date of appearance, in contrast to previous studies.

Moreover, Pound and Zeckhauser (1990) and Kymez (2001) suggest that the price reaction before the date of rumor announcements could be explained by the leaking of information leading to the private use of rumors before these are published. According to Kiymaz (2001), it is mainly financial analysts who covertly spread information among their clients and relatives. In this context, a survey carried out among financial analysts and brokers in the U.S. market revealed that the first channel used for the spread of rumors was the telephone, followed by the media (Shindler, 2007).

The price reaction before the appearance of rumors, however, could stem from certain investors' behavior, whether operators or parties involved in the bid, who adopt a pump-and- dump strategy. The idea is to buy a number of shares from a company, then launch rumors or purchase recommendations through spam or Internet forum discussions in order to attract potential investors. The latter fall into the trap; they buy an important number of shares, which will abruptly drive up the share price. The unscrupulous speculator, source of these financial movements, then simply sells the shares bought at a low price. This strategy, seen as price manipulation ${ }^{12}$ and dissemination of unfounded information, is punishable by the AMF.

\footnotetext{
${ }^{12}$ Among our sample companies, an inquiry was launched in 2005 following Alcan's public offer to acquire Pechiney. The rumors had been circulating since 2003. The investigations regarding the case of Danone in 2005 demonstrated that the rumors came from the sister of the then $\mathrm{CEO}$ of Danone, who was the editor-in-chief of Challenges.
} 
Table 3. Average abnormal returns in the study window $[-5,+5]$

\begin{tabular}{|c|c|c|c|c|c|c|c|}
\hline Days & AAR (\%) & Wilcoxon & $p$ & Sign & $p$ & Student & $p$ \\
\hline-5 & 0.35 & 0.57 & 0.57 & 0.07 & 0.94 & 1.57 & 0.12 \\
\hline-4 & -0.24 & -0.19 & 0.85 & -0.22 & 0.82 & -0.55 & 0.58 \\
\hline-3 & $-0.19^{*}$ & -1.51 & 0.10 & -1.11 & 0.27 & -1.87 & 0.06 \\
\hline-2 & -0.02 & -0.53 & 0.60 & -0.37 & 0.71 & 0.30 & 0.76 \\
\hline-1 & $0.58 * * *$ & 3.17 & 0.00 & 3.04 & 0.00 & 2.08 & 0.04 \\
\hline 0 & $2.66 * * *$ & 7.73 & 0.00 & 6.00 & 0.00 & 3.99 & 0.00 \\
\hline 1 & 0.34 & -0.51 & 0.61 & -0.30 & 0.77 & 1.45 & 0.15 \\
\hline 2 & -0.06 & 0.44 & 0.66 & 0.96 & 0.34 & 0.13 & 0.89 \\
\hline 3 & -0.08 & 0.97 & 0.33 & -0.82 & 0.41 & -1.00 & 0.32 \\
\hline 4 & 0.27 & -0.27 & 0.79 & -0.30 & 0.77 & 1.57 & 0.12 \\
\hline 5 & -0.14 & 0.93 & 0.36 & 1.11 & 0.27 & -0.08 & 0.93 \\
\hline \multicolumn{8}{|c|}{200} \\
\hline
\end{tabular}

Notes: Average abnormal returns (AAR) correspond to the average of the differences between the actual share returns and the market modelestimated returns. The date 0 corresponds to the day a rumor appeared in the various sources. The significance of the average abnormal returns (AAR) is validated in terms of the non-parametric tests of Wilcoxon signed rank-test and the Sign test. The values of the tests are similar, but the interpretation of the findings follows the Wilcoxon signed rank-test, since this test takes into account not only the sign of the variables but also their rank in relation to the whole sample.

$* * *$ significance at $1 \% ; * *$ significance at $5 \%$, and $*$ significance at $10 \%$.

Figure 1. Abnormal returns in the window $[-10,+10]$

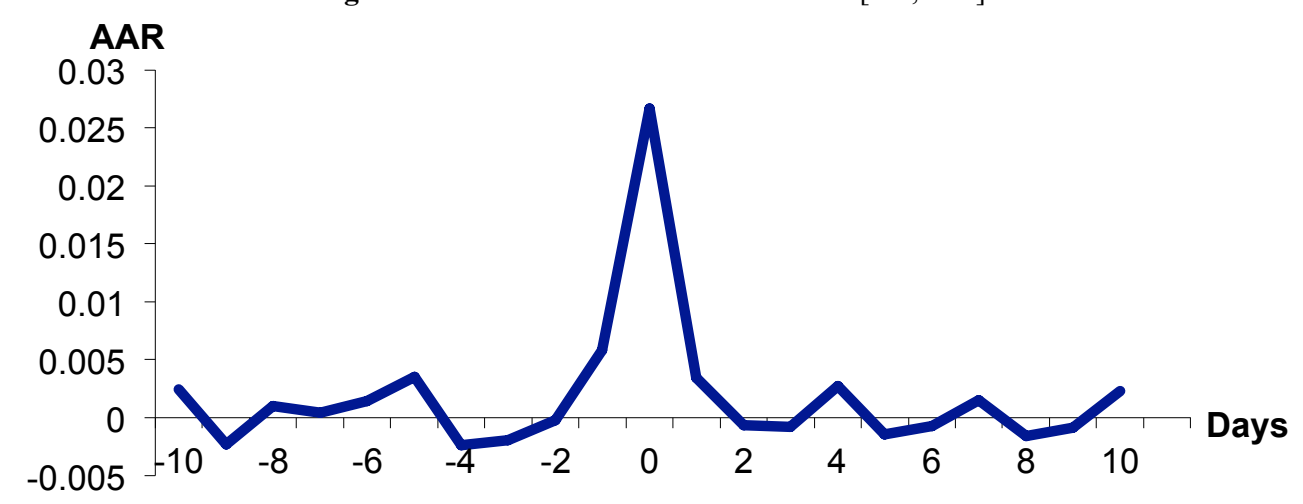

\section{Short-Term Performance Of The Target Stock Prices}

Results show that the price reaction in the rumor post-appearance period is significantly positive in the majority of study windows. This is validated by the significant values of the abnormal returns generated through the buy-andhold strategy that better represent the reality of the investment (Barber and Lyon, 1997)

Table 4. Measures of the performance of the target companies subject to rumors in the post-announcement period

\begin{tabular}{lcccc}
\hline \multicolumn{1}{c}{ Windows } & BAHAR (\%) & Wilcoxon & Sign & 罗 \\
\hline$[0 .+10]$ & $2.51^{* * *}$ & 3.53 & 2.61 & 3.65 \\
{$[0 .+20]$} & $3.34^{* * *}$ & 2.85 & 1.86 & 3.70 \\
{$[0 .+30]$} & $2.61^{* *}$ & 1.86 & 0.52 & 2.42 \\
{$[0 .+40]$} & 2.22 & 3.53 & 2.31 & 1.86 \\
{$[0 .+50]$} & $4.04 * * *$ & 3.07 & 0.00 & 3.03 \\
{$[0 .+60]$} & 1.74 & 0.84 & 1.27 & 0.99 \\
{$[0 .+70]$} & 2.82 & 1.44 & 1.27 & 1.29 \\
{$[0 .+80]$} & 2.16 & 0.96 & 0.82 & 1.07 \\
{$[0 .+90]$} & 1.72 & 0.68 & 0.67 & 0.80 \\
{$[0 .+100]$} & 0.68 & 0.29 & 0.52 & 0.32 \\
{$[0 .+150]$} & -4.21 & -1.12 & & -1.33 \\
\hline
\end{tabular}


Notes: The BAHARs show the abnormal returns of the buy-and-hold calculated in the various windows. The Sign test, the Wilcoxon signed rank-test, and the cross-sectional Student test are applied to validate the significance of returns. *** significance at $1 \%$, **significance at $5 \%$, * significance at $10 \%$.

Figure 2. Short-term performance of the target stock prices subject to rumors

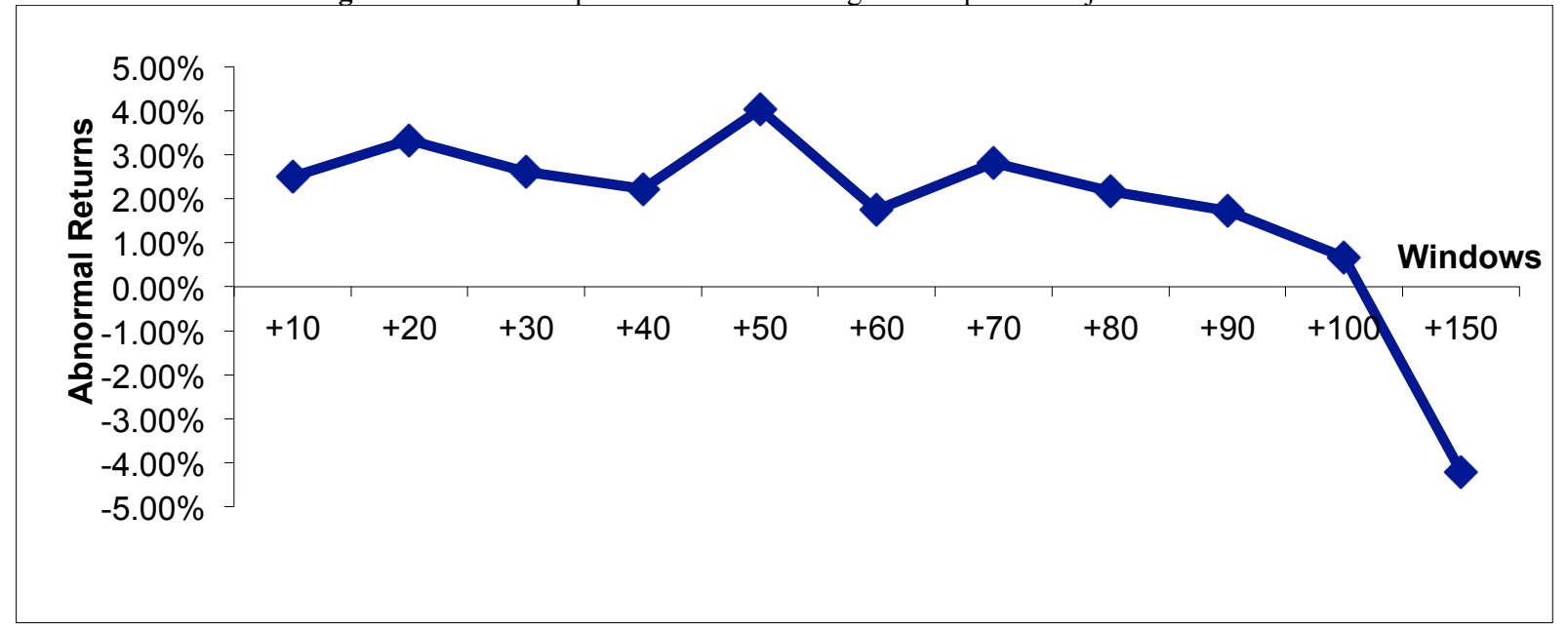

Results indicate that the share prices show a positive reaction from the first 10 days, with abnormal returns of BAHARs of $2.51 \%$ significantly positive at $1 \%$. The increase of the share prices continues and reaches its peak at about the 50th day after the first appearance of the rumors in the market. At that date, the abnormal returns generated by the buy-and-hold strategy reach $4.04 \%$ and are significant at the $1 \%$ level. From the 60 th day, prices start falling, and the abnormal returns generated by the buy-and-hold strategy in the window $[0,+60]$ remain positive though not significant.

Our results thus show that the best investment strategy is to buy the target stock prices the day takeover bid rumors appear in the media and sell 50 days later; the abnormal returns thus generated amount to $4.04 \%$. Nevertheless, this performance is inferior to that found by Gao and Older (2008) after holding the shares for 70 days (4.5\%) and by Zivney et al. (1996) after 80 days (6.35\%).

By the same logic, the strategy of holding the target stock prices beyond 100 days after the first appearance of the rumors does not bring benefits to the investors. The performance observed at 150 days is not significant. This finding is in line with those of Pound and Zeckhauser (1990), Zivney et al. (1996) and Gao and Older (2008). These studies have shown there were no positive and significant abnormal returns in the period beyond 100 days after the first rumor appearance.

Determining Factors of the Gain for the Target Shareholders

Table 5 shows significant relations between the abnormal returns calculated 50 days after the first rumor appearance and certain variables of the three categories, namely credibility, rumor characteristics, and expected takeover effects. 
Table 5. Determining factors of short-term performance

\begin{tabular}{l|c|ccc}
\hline \multirow{2}{*}{ Components } & Variables & coefficients & $\boldsymbol{t}$ & $\boldsymbol{p}$ \\
\cline { 2 - 5 } Credibility & (Constant) & -0.071 & -1.096 & 0.275 \\
& SIZE & $-0.006^{*}$ & -1.645 & 0.102 \\
& SECT & -0.023 & -0.964 & 0.337 \\
& FLOTT & $0.015^{* *}$ & 2.353 & 0.020 \\
Characteristics & SEV & $-0.013^{* *}$ & -2.204 & 0.029 \\
& SC & $0.037^{* *}$ & 1.983 & 0.049 \\
& ARG & $0.040^{* *}$ & 2.076 & 0.040 \\
Expected effects (interests) of the & PERIO & $0.057^{* * *}$ & 2.878 & 0.005 \\
takeover & REG & $-0.044^{* * *}$ & -2.092 & 0.038 \\
\hline \multirow{2}{*}{ Model statistics } & ENDTT & $-0.012^{* *}$ & -1.856 & 0.065 \\
& FCF & 0.039 & 1.075 & 0.284 \\
& R & $0.090^{* * *}$ & 2.204 & 0.029 \\
\hline
\end{tabular}

Notes: $S I Z E$ indicates the size of the target company as measured in terms of the total assets logarithm. $S E C T$ is a binary variable equal to 1 if the target belongs to a sector targeted by a takeover bid during the year preceding the appearance of rumors and to 0 if not. Flott, is the square root of the free float and determines the percentage of the target capital released to the public and not held by the main shareholders. $S E V$ is a variable that measures the undervaluation of the target; it is expressed in terms of the market-to-book ratio. $S C$ is a binary variable that shows the dissemination intensity; it is equal to 1 if the rumor has appeared in several sources and to 0 if not. $A R G$ is a binary variable equal to 1 if the rumor is accompanied by details concerning the motivation behind the bid and to 0 if not. PERIO is a binary variable equal to 1 if the rumor appeared during the first five months of the year and to 0 if not. $R E G$ is a binary variable equal to 1 if the rumor appeared after October 2006 (the date of the implementation of the law regarding takeover rumors) and to 0 if not. ENDETT shows the debt capacity of the target companies; it is measured by the long-term debt/ equity capital ratio. FCF shows a possible agency issue of the target companies, particularly in the case of accumulated free cash flow; the variable is expressed through the free cash flow/total assets ratio.

$* * *, * *, *$ : statistics are significant at the $1 \%, 5 \%$, and $10 \%$ level respectively.

In terms of rumor credibility, the negative sign of the coefficient of the SIZE variable shows a negative relationship with the abnormal returns observed; this finding is aligned with the results found by Clarkson et al. (2006). In this perspective, the investors' reaction is greater when the rumor targets small-sized companies. This notion is supported by the results of studies focusing on the profiles of target companies that show the negative relationship between the likelihood of acquisition and the size of the target (Palepu, 1986; Hansen 1987). Furthermore, results show that the sector affiliation of the targets does not appear to have a significant link with the abnormal returns observed. In contrast, the free float percentage explains positively the short-term performance of the companies subject to takeover rumors. These rumors gain credibility when the target capital is widely disseminated among the public, thus increasing the likelihood of acquisition. A negative link is also found between the book-to-market ratio and the BAHARs $(0,+50)$; the price reaction is all the stronger when the rumors target, inter alia, undervalued shares. Undervaluation of target shares is among the supporting assumptions linked to takeover operations (Hasbrouck, 1985). A low market-to-book ratio means that the share market value does not show its real value, which will encourage the predatory practices of some companies wishing to acquire at lower prices.

When considering the "rumor characteristics component", results show the positive influence of the intensity of publication, rationale, and the time of appearance of the rumors on the observed performance. The investors' gain is all the more important if the rumor (1) is carried by several media in the first few days, (2) is accompanied by evidence that justifies its presence on the market and reinforces its credibility, and (3) has appeared during the first five months of the year, more particularly in January and April. In addition to these three variables, rumor characteristics are also expressed in terms of the REG variable. The latter's coefficient is negative and shows a short-term loss of performance of the target stock prices subject to takeover rumors after the year $2006 .{ }^{13}$ In part, this result attests to the effectiveness of the law passed by the AMF and designed to reduce the excessive price volatility of target companies confronted by this type of rumors.

The last component, "expected results (interests) of the takeover" shows the rationale for the takeover and possibly for the emergence of rumors. Three main hypotheses explaining growth operations have emerged in the literature:

${ }^{13}$ Before that period, abnormal returns observed over 50 days reached $6 \%$ on average. 
synergy effects, the effectiveness of the management team, and agency issues. The regression results indicate a significant negative effect of indebtedness shown in terms of the long-term debt/equity ratio. Hence, the stronger the price reaction, the less indebted the company is. In this particular case, acquiring the target is motivated by its spare debt capacity, which represents a potential source of funding for the buyers, which then explains the synergy effect (Palepu, 1986; Barnes, 1999). This is borne out by the positive relationship between the abnormal returns and the free cash flow level that is available in the target company. As acquisition is explained by the accumulation of free cash flow, there is evidence of an agency issue (Jensen, 1988). Investors react far more to rumors that target companies with surplus liquidity that appears as a source of funding for buyers. The last variable in the category of "expected results (interests) of the takeover" relates to the lack of effectiveness of the target's management team. Results show a non significant positive relationship between Tobin's $Q$ ratio and abnormal returns.

\section{CONCLUSION}

Over the last few years, the French Stock Exchange has been particularly hit by an important phenomenon, namely takeover bid rumors. Following the emergence of rumors concerning their potential acquisition, groups such as Hermès, Société Générale or Danone have experienced excessive share price volatility. Since 2006, attesting to the seriousness of the issue, the AMF has set in place a specific management mechanism to deal with this type of rumors.

In this context, the main goal of our study was to examine the short-term performance of companies subject to takeover rumors and to identify their determining factors. The study thus covered the French Stock Exchange and focused on 200 rumors collected between 1997 and 2011, using the Factiva database.

The results of the event study show positive abnormal returns around the date of appearance of the rumors in the media. Our findings also show that the price reaction reaches its peak around the 50th day after that date. Holding stock prices targeted by this type of operation thus proves to be highly beneficial to investors, bringing an average gain of almost $4 \%$.

Based on hypotheses predicting takeovers and on the determining factors for the premium offered to the shareholders of the target companies, we have also presented a model designed to examine the variations of the abnormal performance of target companies over the period following the appearance of the takeover rumors. Three categories of explanatory variables were identified: credibility, rumor characteristics, and expected results (interests) of the takeover.

We found that the investors' potential gain varies positively with the free float, the intensity of publication, the rationale presented, the time of appearance, and the free cash flow level of the target. Conversely, a negative gain relation was found with the market-to-book ratio and the size of targets. The shareholders' premium tends to diminish after 2006, in other words after the implementation of the law concerning declarations of intent related to takeover rumors.

Our various results and the perspectives of stock agencies have indicated that the rumor management procedure has eventually enabled the partial cushioning of the impact of takeover rumors. Hence, we support the French legislative direction promoting the strengthening of regulations concerning the management of this type of information. In the meantime, the shareholders of target companies and the portfolio managers will continue using these rumors to speculate and optimize their investment strategies, taking into account the performance determining factors we have identified. 


\section{AUTHOR INFORMATION}

Mhammed Laouiti, Professor of Finance at Faculty of Economics and Management of Sfax. Ph.D. (Management Sciences-Finance), University of Montesquieu- Bordeaux IV. His major publications include the market liquidity, corporate governance and rumors on financial markets. E-mail: laouitimhamed@voila.fr

Badreddine MSOLLI, Professor of Finance at ESSCA- School of management- Lunam university. Member of the Research Laboratory LUNAM-University, Ph.D. (Management Sciences-Finance at University of MontesquieuBordeaux IV). His major publications include the capital restructuring, crowdfunding and financial markets. His research interests are on crowdfunding, capital markets and market liquidity. E-mail: Badreddine.MSOLLI@essca.fr

Aymen Ajina, Ph.D. (Management Sciences-Finance), Professor of Finance at Arab East Colleges-Riyad, Saudi Arabia. PhD at HEC Management School- University of Liège. Member of the Research Laboratory LAMIDEDUniversity of Sousse. His major publications include the Markets and Investors, International Management, and The International Journal of Managerial Finance among others. His research interests are on corporate governance, financial disclosure and market liquidity. E-mail: ayman.ajina@gmail.com

\section{REFERENCES}

Armitage S. "Event study methods and evidence on their performance". Journal of economic surveys, Vol. 9, 1995, pp. $25-52$.

Barber B. and Lyon., "Detecting Long-Run Abnormal Stock Returns: The Empirical Power and Specification of Test Statistics", Journal of Financial Economics, 43(3), 1997, pp.341-372.

Barnes P., "Predicting UK Takeover Targets: Some Methodological Issues and an Empirical Study", Review of Quantitative Finance and Accounting, Vol. 12, 1999, pp.283-301.

Brown J. and Warner J., "Using daily stock returns: the case of event Studies", Journal of Financial Economics, vol 14, 1985, pp. 3-31.

Clarkson, Joyc and Tutticci., "Market reaction to takeover rumor in Internet Discussion Sites", Accounting \& Finance. Vol. 46 (1),2006, pp. 31-52

Cudd M. and Duggal R., "Industry Distributional Characteristics of Financial Ratios: an Acquisition Theory Application", The Financial Review, vol. 41, 2000, pp.105-120.

Fama. E., Fisher L., Jensen M. and Roll. R., "The Adjustment of Stock Prices to New Information", International Economic Review, Vol. 10, No. 1, 1969, pp. 1-21

Gao Y, and Older D., "Rumors and Pre-Announcement Trading., "Why sell target Socks before acquisition announcements?", research paper, university of Indiana, June, 2008.

Goergen M. and Renneboog L., "European Financial Management", Vol. 10, No. 1, 2004, pp. 9-45.

Hasbrouck J., "The characteristics of takeover targets: UqU and other measures", Journal of Banking and Finance, Vol. 9, 1985, pp. 351-362.

Jarrell G. and Poulsen A., "Stock trading before the announcement of tender offers: Insider trading or market anticipation?" , Journal of Law, Economies and Organisation 5,1989, pp. 225-248.

Jensen M ., "Agency costs of free cash-flow, corporate finance, and takeovers", American Economic Review, Vol. 76(2), 1988, pp. 323-29.

Kapferer J., "Les Rumeurs : Le Plus Vieux Média du Monde», Editions du Seuil, 1987, Paris.

Kapferer J., " La rumeur en bourse", Communication, Vol. 52,1990, pp. 61-84.

Keown A. and Pinkerton J., "Merger announcements and insider trading activity: An empirical investigation", Journal of Finance 36(4), 1981, pp. 855-869.

Kimmel AJ., "Rumors and the Financial Marketplace", Journal of Behavioral Finance, No. 5, 2004, pp. $134-141$.

Kiymaz A., " The Effects Of Stock Market Rumors On Stock Prices: Evidence From an Emerging Market", Journal of Multinational Financial Management, Vol 11, Issue 1, 2001, pp 105-115.

Laouiti M., "Profil des entreprises cibles de rumeurs d'offres publiques d'acquisition", La Revue du Financier, vol 36, No 206, 2014, pp. 75-88.

Lehn K. and Poulsen A., " Free Cash Flow and and stcokholder Gains in Going Private Transactions", The Journal of Finance, vol. 44, No. 3, 1989, pp. 771-787

Martynova M. and Renneboog L., "The Performance of the European Market for Corporate Control: Evidence from the Fifth Takeover Wave ", European Financial Management, Vol. 17, No. 2, 2011, pp. 208-259.

Palepu G., "Predicting Takeover Targets: A Methodological and Empirical Analysis", Journal of Accounting and Economics, vol. 8, 1986, pp. 3-35.

Pound J. and Zeckhauser R., "Clearly heard on the street: The effect of takeover rumors on stock prices", Journal of Business 63, 1990, pp. 291-308. 
Powell RG., " Modelling takeover likelihood ", Journal of Business Finance \& Accounting, No. 24,1997, pp. 1009-1030.

Rau P.R. and Vermaelen T., "Glamour, value and the post-acquisition performance of acquiring firms ", Journal of Financial Economics, Vol. 49, 1998, pp. 223-53.

Servaes H., "Tobin's Q and the gains from takeovers", Journal of Finance, Vol. 46(1), 1991, pp. 409-19.

Shindler M., "Rumors in Financial Markets: Insights into Behavioral Finance", John Wiley \& Sons, Ltd, 2007.

Zivney TL.; Bertin WJ and Torabzadeh KM., "Overreaction to takeover speculation", The Quarterly Review of Economics and Finance, No. 36, 1996. pp. 89-115. 


\section{NOTES}

